\title{
Some Diagnostic Features of RUSSIAN HYDROTHERMAL SYNTHETIC RUBIES AND SAPPHIRES
}

\author{
By Karl Schmetzer and Adolf Peretti
}

Most Russian hydrothermal synthetic rubies and pink, orange, green, blue, and violet sapphires - colored by chromium and/or nickelreveal diagnostic zigzag or mosaic-like growth structures associated with color zoning. When the samples are properly oriented, these internal patterns are easily recognized using a standard gemological microscope in conjunction with immersion or fiber-optic illumination. Pleochroism is also useful to separate chromium-free blue-to-green synthetic sapphires from their natural counterparts. Samples colored by a combination of chromium, nickel, and iron are also described.

\section{ABOUT THE AUTHORS}

Dr. Schmetzer is a research scientist residing in Petershausen, near Munich, Germany. Dr. Peretti (aperetti@gemresearch.ch) is director of GRS Gemresearch Swisslab AG, Lucerne, Switzerland.

Acknowledgments: The authors are grateful to the following people for supplying some of the samples used in this study: Fred Mouawad,

Bangkok, Thailand; Christopher P. Smith and

Dr. Dietmar Schwarz, both of the Gübelin

Gemmological Laboratory, Lucerne,

Switzerland; Dr. James E. Shigley, GIA

Research, Carlsbad, California; and the Siberian

Gemological Center, the United Institute of

Geology, Geophysics and Mineralogy, and the

joint venture Tairus, all of Novosibirsk, Russia.

Gems \& Gemology, Vol. 35, No. 1, pp. 17-28

(C) 1999 Gemological Institute of America
$\mathcal{H}$ ydrothermal synthetic ruby of Russian production first appeared on the international market in 1993 (Peretti and Smith, 1993, 1994). Subsequently, in 1995, yellow, orange, blue-green, and blue synthetic sapphires from Novosibirsk became available (figure 1). Recently, these sapphires were described in detail (Peretti et al., 1997; Thomas et al., 1997). As those authors reported, infrared and visible-range spectroscopy, as well as trace-element chemistry, are useful to separate these synthetic sapphires from their natural counterparts. Microscopic examination has also revealed features of diagnostic value, such as copper-bearing particles and flake-like aggregates, as well as various types of fluid and multi-phase inclusions. However, the gemologist does not always have access to sophisticated analytical equipment, and characteristic inclusions are not always present. Therefore the authors decided to investigate the internal growth patterns of this material in an effort to identify distinctive characteristics that might be readily seen in most samples.

Growth patterns in hydrothermal synthetic emeralds, such as those of Russian production, generally are known to gemologists (see Schmetzer, 1988), and irregular growth features in Russian hydrothermal synthetic rubies and sapphires also have been mentioned briefly (Sechos, 1997; Thomas et al., 1997). However, these publications described no specific orientation of the synthetic rubies and sapphires during examination for these features. In the experience of the present authors, the observation of growth features in unoriented samples is sufficient to identify only some hydrothermally grown samples; that is, only heavily disturbed, strongly roiled growth patterns can be observed without a specific orientation (figure 2; see also figure 16 in Thomas et al., 1997, p. 200). These patterns can also be mistaken for growth features seen in natural rubies and sapphires. For oriented samples, however, a diagnostic growth 


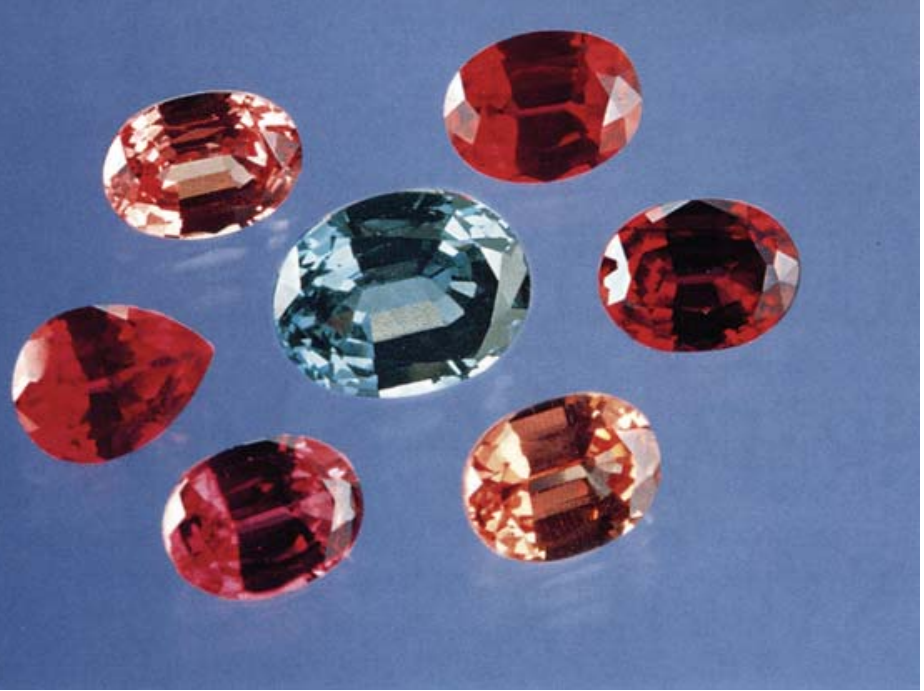

Figure 1. Russian crystal-growth laboratories are now producing hydrothermal synthetic ruby as well as sapphires in a range of colors. The bluegreen sapphire in the center $(9.2 \times 7.0 \mathrm{~mm})$ weighs 2.65 ct. Photo by Maha DeMaggio.

pattern can be seen in most of the synthetic rubies, as well as in a major portion of the synthetic sapphires. Yet few of these growth patterns have been illustrated to date. The present study gives a detailed description of the diagnostic growth features, and describes a method to position a sample so that these features can be readily seen in commercially available Russian hydrothermal synthetic rubies and sapphires (i.e., those colored by chromium and/or nickel).

Differences in pleochroism have been mentioned as being useful to separate some Tairus greenish blue synthetic sapphires from their natural counterparts (Thomas et al., 1997). A pleochroism of weak to strong green-blue to blue was indicated for some of the Tairus samples; however, this is also found in basaltic-type bluish green to blue natural sapphire (see, e.g., Schmetzer and Bank, 1980, 1981). Consequently, we also re-evaluated the applicability of pleochroism to the identification of synthetic Russian hydrothermal rubies and sapphires.

\section{MATERIALS AND METHODS}

The 83 samples studied were reportedly produced either at the United Institute of Geology, Geophysics and Mineralogy, Novosibirsk, Russia, or at the hydrothermal growth facilities of Tairus Co., also in Novosibirsk. Forty-two samples were acquired between 1993 and 1996 by one of the authors (AP) during various stays in Bangkok and Novosibirsk (see Peretti et al., 1997). Two additional synthetic rubies were purchased in 1998 at Tairus Co., Bangkok, Thailand; and a collection of 17 samples, loaned by C. P. Smith, contained hydrothermal synthetic rubies and sapphires obtained from 1993 to 1998 in Novosibirsk and Bangkok. A set of 22 faceted samples from the GIA research collection originated directly from Tairus Co., Novosibirsk; 18 of these were used in the report by Thomas et al. (1997).

The samples included six complete synthetic ruby (2) and synthetic sapphire (4) crystals grown on tabular seeds (see, e.g., figure 3), as well as two crystals that were grown on spherical (Verneuil) seeds specifically for the study of crystal growth. The eight crystals ranged from about 6 to 59 ct. Twentytwo of the samples were irregular pieces that had been sawn from larger crystals, and 12 samples were plates that had been polished on both sides. Most of these 34 irregular pieces and plates contained a portion of a colorless tabular seed. A polished window was prepared on about 15 of the crystal fragments (the largest of which was $41 \mathrm{ct}$ ) for microscopic examination. The remaining 41 synthetic rubies and sapphires of various colors were faceted and ranged from 0.22 to $4.72 \mathrm{ct}$ (see, e.g., figure 1).

To characterize the samples according to their cause of color and trace-element contents, we obtained ultraviolet-visible (UV-Vis) spectra for about half the 41 synthetic rubies and pink sapphires, and all the 42 synthetic sapphires, by means of a Leitz-Unicam SP 800 UV-Vis spectrophotometer. We performed trace-element analysis by energydispersive X-ray fluorescence (EDXRF), using a Tracor Northern TN 5000 system, for 32 samples that included each color variety and/or each type of absorption spectrum.

Figure 2. If a hydrothermal synthetic sapphire or ruby is not oriented in a specific direction when it is examined with magnification and fiber-optic illumination, as seen in this Russian synthetic sapphire, the growth patterns are difficult to resolve and may mimic those seen occasionally in natural corundum. Magnified 40x.

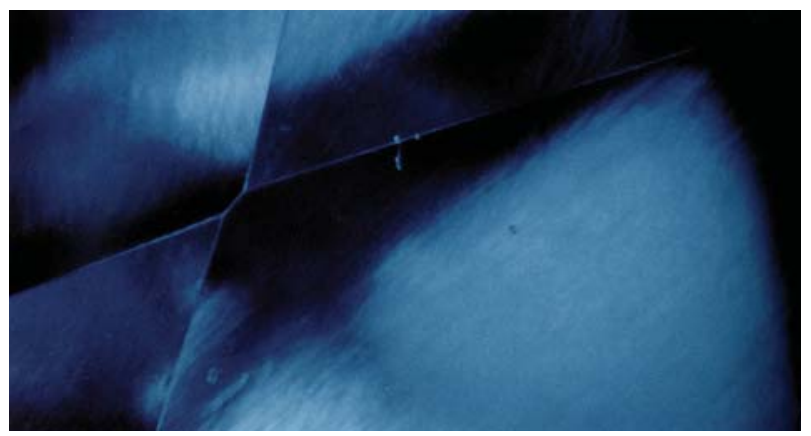


To document a possible color change by gammairradiation, we exposed one intense blue-green synthetic sapphire to ${ }^{60} \mathrm{Co}$ in a commercial irradiation facility.

Morphological characteristics of the complete crystals were measured with a goniometer. The external faces of the smaller sawn pieces, the polished plates, and the internal growth patterns of all 83 samples were examined with a Schneider horizontal (immersion) microscope with a specially designed sample holder and specially designed eyepieces (to measure angles: Schmetzer, 1986, and Kiefert and Schmetzer, 1991; see also Smith, 1996). We also examined many of the samples with an Eickhorst gemological microscope (without immersion) using fiber-optic illumination.

Most of the faceted samples were cut with their table facets at various oblique angles to the c-axis of the original crystal. Consequently, we determined the pleochroism of all the faceted samples in immersion with the following three-step procedure: (1) using crossed polarizers, we oriented the c-axis parallel to the direction of view by observation of the variation in interference rings as the sample was rotated (see Kiefert and Schmetzer, 1991); (2) we rotated the sample through $90^{\circ}$ about the vertical axis of the sample holder to orient the c-axis in the east-west direction of the microscope, and then removed one polarizer; and (3) we determined both pleochroic colors by rotating the remaining polarizer.

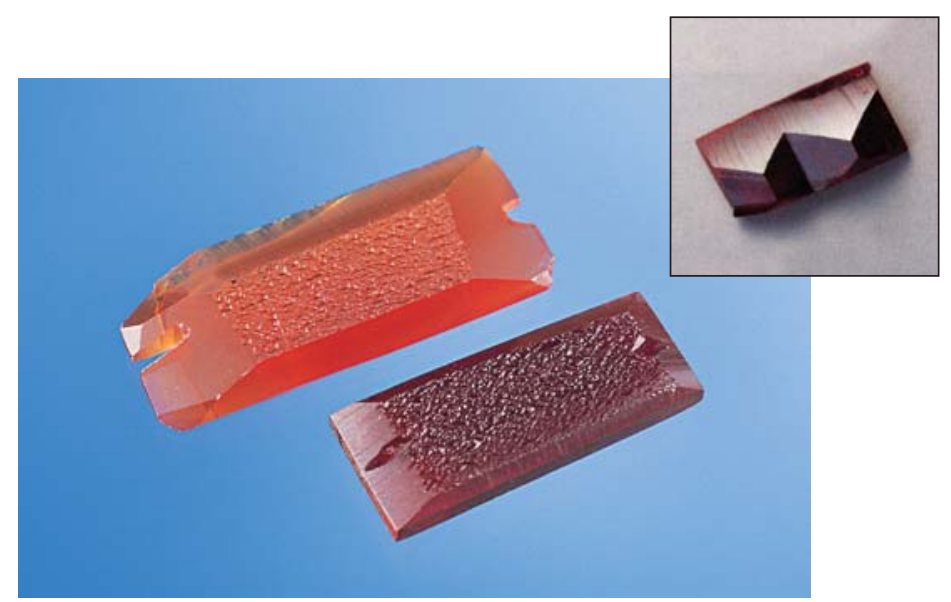

Figure 3. These three samples are representative of the Russian hydrothermal synthetic ruby and sapphire crystals grown on tabular seeds. Two standard seed orientations are used: The $31 \times 13 \mathrm{~mm}$ synthetic ruby on the bottom was grown with a seed parallel to a prism $\mathrm{b}\{10 \overline{1} 0\}$, whereas the orange synthetic sapphire $(40 \times 18 \mathrm{~mm})$ and the synthetic ruby in the inset $(35 \times 18 \mathrm{~mm})$ were grown with seeds parallel to a negative rhombohedron $-\mathrm{r}\{01 \overline{1} 1\}$. The rough, uneven faces of two of the crystals are oriented parallel to the seed; by contrast, the crystal in the inset reveals alternating hexagonal dipyramids $\mathrm{n}\{22 \overline{4} 3\}$. Photo $@$ GIA and Tino Hammid; inset by M. Glas.

\section{RESULTS AND \\ DISCUSSION}

Characterization of Samples According to Color and Cause of Color. On the basis of color, absorption

\begin{tabular}{|c|c|c|c|c|}
\hline Color & Cause of color & Pleochroism || c-axis & Pleochroism $\perp$ c-axis & Samples ${ }^{a}$ \\
\hline Ruby and pink sapphire & $\mathrm{Cr}^{3+}$ & Yellowish red to orange & Red to purplish red & $\begin{array}{c}15 \text { pieces, } 14 \text { faceted, } \\
8 \text { plates, } 2 \text { crystals, } \\
2 \text { crystals with spherical } \\
\text { seeds }\end{array}$ \\
\hline $\begin{array}{l}\text { Reddish orange to } \\
\text { orange-pink sapphire }\end{array}$ & $\mathrm{Cr}^{3+}, \mathrm{Ni}^{3+}$ & Light reddish yellow & Intense reddish orange & 5 faceted \\
\hline Orange sapphire & $\mathrm{Cr}^{3+}, \mathrm{Ni}^{3+}$ & Light yellowish orange & Intense orange & 2 crystals, 1 faceted \\
\hline Yellow sapphire & $\mathrm{Ni}^{3+}$ & Yellow & Yellow & 4 faceted \\
\hline Green sapphire & $\mathrm{Ni}^{2+}, \mathrm{Ni}^{3+}$ & Yellowish orange & Yellowish green & 1 piece, 1 faceted \\
\hline Bluish green sapphire & $\mathrm{Ni}^{2+}, \mathrm{Ni}^{3+}$ & Orange & Green & 2 faceted \\
\hline Blue-green sapphire & $\mathrm{Ni}^{2+}, \mathrm{Ni}^{3+}$ & Reddish orange & Bluish green & 1 piece, 2 faceted \\
\hline Blue sapphire & $\mathrm{Ni}^{2+}$ & Reddish violet & Blue-green & 1 plate, 3 faceted \\
\hline Blue-violet sapphire & $\mathrm{Ni}^{2+}, \mathrm{Cr}^{3+}$ & Reddish violet & Blue & 1 piece, 2 faceted \\
\hline Bluish violet sapphire & $\mathrm{Ni}^{2+}, \mathrm{Cr}^{3+}$ & Violetish red & Bluish violet & 3 faceted \\
\hline Violet sapphire & $\mathrm{Ni}^{2+}, \mathrm{Cr}^{3+}$ & Violetish red & Violet & 1 faceted \\
\hline
\end{tabular}

a "Crystals" were complete, and grown on tabular seeds; rough "pieces" were sawn from crystals grown on tabular seeds; and thin "plates" were polished on both sides. 


\section{BOX A: CHARACTERIZATION OF RUSSIAN HydROTHERMAL SYNTHETIC SAPPHIRES COLORED By CHROMIUM, NICKEL, AND IRON}

The three synthetic corundum samples that were found to contain a combination of chromium, nickel, and iron consisted of two color-change synthetic sapphires (one rough and one faceted) and one bluish violet synthetic sapphire crystal.

Color-Change Samples. The seed in this crystal was oriented differently from those in the crystals from the main sample. This crystal showed an uneven face that was oriented perpendicular to a large $r$ face; consequently, the seed must have been cut perpendicular to $r$. The internal growth patterns of the faceted color-change sample indicate the same seed orientation. Such a seed orientation has not been observed in other chromium- and/or nickel-bearing Russian synthetic rubies or sapphires.

The color-change synthetic sapphires (figure A1) were bluish green in day (or fluorescent) light and reddish violet in incandescent light. There was only a weak change in these colors when the samples

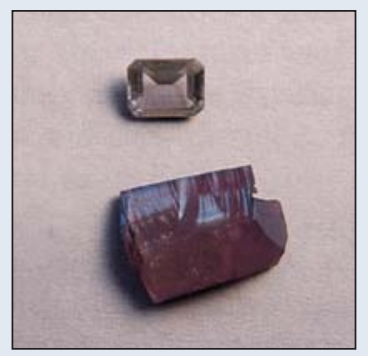

Figure A-1. These colorchange synthetic sapphires are colored by iron, chromium, and nickel. The faceted sample weighs $2.89 \mathrm{ct}$. Incandescent light; photo by M. Glas.

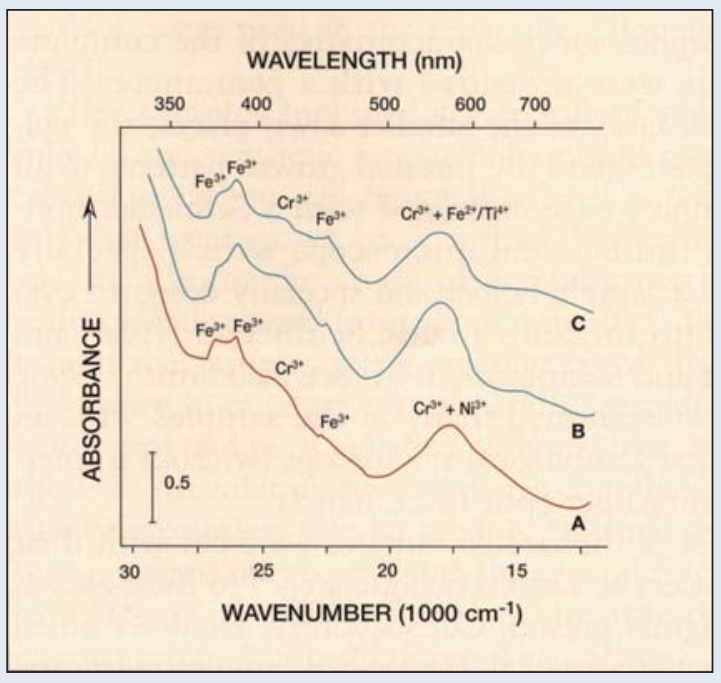

Figure A-2. The absorption spectrum of this color-change hydrothermal synthetic sapphire $(A)$ is very similar to the spectra ( $B$ and $C$ ) of natural color-change sapphires (in this case, from Mercaderes, Colombia). The synthetic sapphire reveals absorption bands of $\mathrm{Fe}^{3+}$, $\mathrm{Cr}^{3+}$, and $\mathrm{Ni}^{2+}$, whereas the natural samples are colored by $\mathrm{Fe}^{3+}, \mathrm{Cr}^{3+}$, and $\mathrm{Fe}^{2+} / \mathrm{Ti}^{4+}$ pairs. The maximum caused by $\mathrm{Cr}^{3+}$ and $\mathrm{Ni}^{2+}(A)$ is slightly shifted to higher wavelengths compared to the peak caused by $\mathrm{Cr}^{3+}$ and $\mathrm{Fe}^{2+} / \mathrm{Ti}^{4+}$ (B and $C$ ). spectroscopy, and trace-element analysis, we found that 71 of the 83 samples were colored predominantly by chromium and/or nickel (table 1). Synthetic ruby and sapphires containing these elements are now commercially produced by Tairus Co. at Novosibirsk. Three of the remaining 12 samples are described in Box A; these samples are colored by chromium, nickel, and iron. The remaining nine synthetic sapphires did not contain chromium and/or nickel as color-causing trace elements. Therefore, these samples are not described here.

On the basis of their color, absorption spectra, and trace-element contents, we separated the 71 commercially available samples into six color "varieties:" ruby-pink sapphire and reddish orange to orange, yellow, green to blue-green, blue, and blue- violet to violet sapphire (again, see table 1). Although traces of iron were detected by EDXRF in these samples, no $\mathrm{Fe}^{3+}$ absorption bands were observed. Consequently, the influence of iron on their color is negligible. EDXRF analyses revealed various amounts of chromium-but no nickel-in the synthetic rubies and pink sapphires. In the yellow, green, blue-green, and blue samples, traces of nickel only were present as color-causing elements, whereas the blue-violet to violet and the orange to reddish orange synthetic sapphires contained traces of both chromium and nickel. These chemical properties are comparable to analytical data published by Thomas et al. (1997).

The absorption spectra were consistent with our chemical data as well as with the interpretation of 
were viewed parallel and perpendicular to the caxis; that is, the colors were more intense parallel to c. These samples were found to be heavily irondoped members of the chromium-nickel series. Their absorption spectra showed the dominant $\mathrm{Ni}^{2+}$ absorption band of blue synthetic sapphire superimposed on minor $\mathrm{Cr}^{3+}$ and $\mathrm{Fe}^{3+}$ absorption bands (figure A-2). With an absorption maximum in the yellow and minima in the red and blue-green areas of the visible region, this spectrum reveals all the features associated with color change in a mineral (see, e.g., Schmetzer et al., 1980; Hänni, 1983). In natural color-change sapphire (e.g., from Mercaderes, Colombia), this particular spectrum is caused by $\mathrm{Fe}^{2+} / \mathrm{Ti}^{4+}$ absorption bands of blue sapphire superimposed on $\mathrm{Cr}^{3+}$ and $\mathrm{Fe}^{3+}$ absorption bands (figure A-2; Schmetzer et al., 1980; see also Keller et al., 1985). In the authors' experience, natural colorchange samples from Sri Lanka and Tanzania (Umba and Tunduru-Songea areas) have almost identical spectra.

The growth patterns of both samples (figure A3) were comparable to the patterns seen in samples of the chromium-nickel series (see, e.g., figures 13 and 15), with subparallel striations and subgrain boundaries between microcrystals observed in both. However, unlike the color zoning seen in samples grown with one of the two standard seed orientations (see, e.g., figure 8), these two samples revealed color zoning at an inclination to the dominant subgrain boundaries.

Bluish Violet Sample. This crystal consists of a thin overgrowth of synthetic corundum over a tabular seed with an orientation parallel to $-r$. Typical irregular surface features representing subindividuals were seen on both $-r$ faces parallel to the seed plate. The pleochroic colors were violet perpendicular to the c-axis, and yellow parallel to the c-axis. The color of the crystal is a complex function of superimposed $\mathrm{Cr}^{3+}, \mathrm{Ni}^{2+}$, and $\mathrm{Fe}^{3+}$ absorption bands; the absorption spectrum is comparable to that of bluish violet sapphires of the chromium-nickel series, with additional subordinate $\mathrm{Fe}^{3+}$ absorption bands. This sample was higher in chromium than the two colorchange synthetic sapphires.
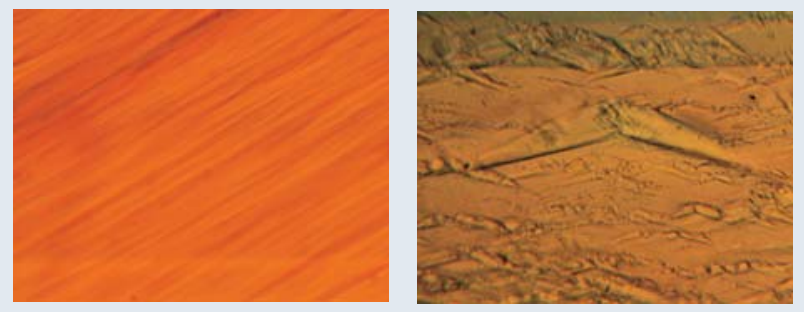

Figure A-3. The growth patterns in the colorchange synthetic sapphires were similar to those seen in the synthetic samples of the series. Subparallel striations (left) were observed in the faceted sample at $70 \times$ magnification. A zigzag pattern (right) was visible in the crystal in a view parallel to the striations at 50× magnification (both with immersion). color causes by Thomas et al. (1997). * Our samples are represented in a triangular diagram (figure 4), with basic colors caused predominantly by $\mathrm{Cr}^{3+}$ (rubies and pink sapphires), $\mathrm{Ni}^{3+}$ (yellow sapphires), and $\mathrm{Ni}^{2+}$ (blue sapphires). Intermediate synthetic sapphires colored by a combination of $\mathrm{Cr}^{3+}$ and $\mathrm{Ni}^{3+}$ (reddish orange to orange), $\mathrm{Ni}^{3+}$ and $\mathrm{Ni}^{2+}$ (green to blue-green), and $\mathrm{Ni}^{2+}$ and $\mathrm{Cr}^{3+}$ (blue-violet to violet) are arranged along the edges of the triangle. Thomas et al. (1997) described all samples of the $\mathrm{Ni}^{2+}-\mathrm{Cr}^{3+}$ series as greenish blue. However, we feel that samples of this series are better described as blue, blueviolet, bluish violet, and violet (see figure 4 and table 1). Intermediate samples with high chromium and small $\mathrm{Ni}^{2+}$ contents, as well as samples with high amounts of $\mathrm{Ni}^{3+}$ and smaller $\mathrm{Ni}^{2+}$ contents, were not observed in this study. An intense bluegreen sample, however, turned intense yellowish green on $\gamma$-irradiation, which can be explained by conversion of part of the $\mathrm{Ni}^{2+}$ to $\mathrm{Ni}^{3+}$ (see Thomas et al., 1997).

For comparison, the natural counterparts of these synthetic rubies and sapphires are represented in another triangular diagram, with red to pink, yellow, and blue to blue-violet in the three corners (figure 5). This diagram is based on several thousand absorption spectra recorded over a 25 year period by one of the authors (KS; mostly unpublished), from

\footnotetext{
* The polarization of the spectrum of a greenish blue synthetic sapphire is erroneously reversed in figure $5 \mathrm{~A}$ in the Thomas et al. (1997) article.
} 


\section{Coloration of Hydrothermal Synthetic Corundum}

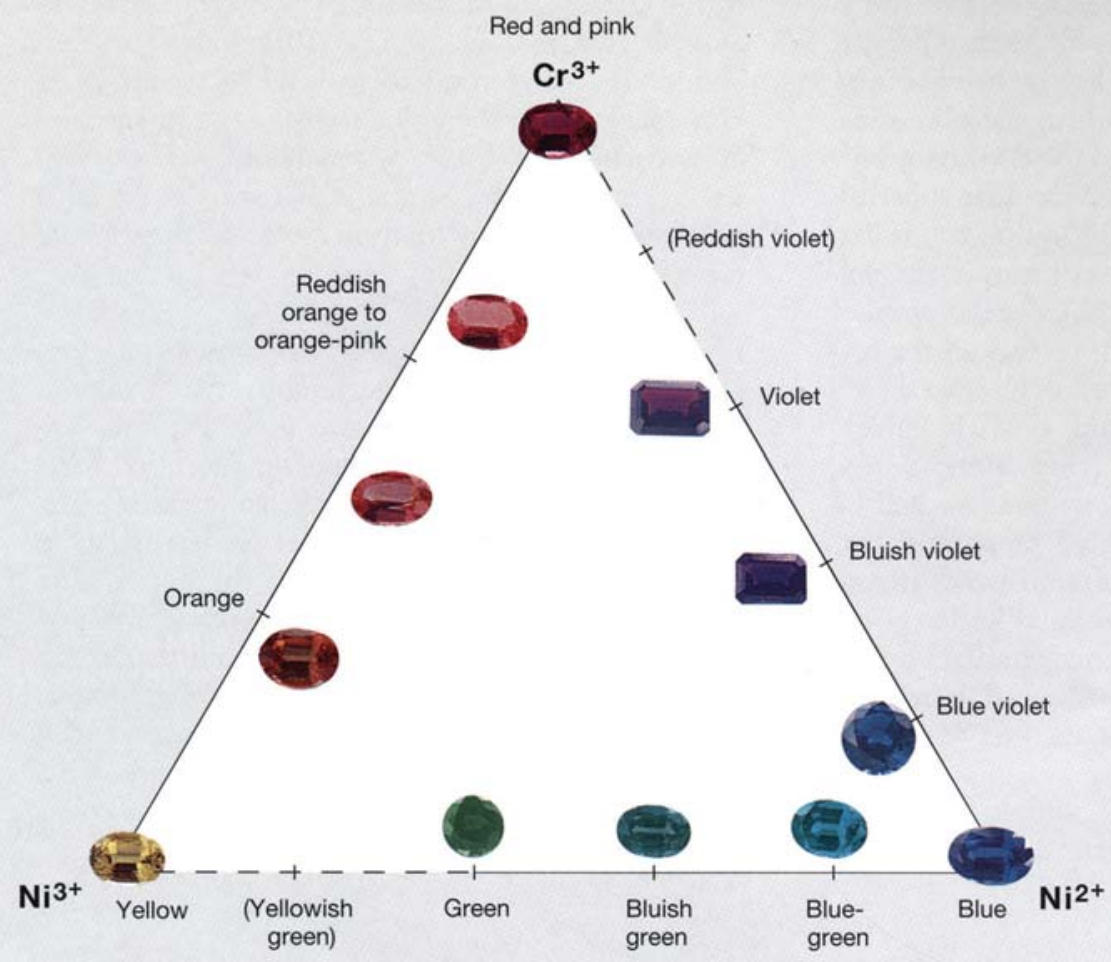

Figure 4. This triangular diagram shows the varieties of Russian hydrothermal synthetic corundum that are colored by chromium and nickel. The three basic chromophores are labeled at the corners of the triangle, namely $\mathrm{Cr}^{3+}$ (red to pink), $\mathrm{Ni}^{3+}$ (yellow), and $\mathrm{Ni}^{2+}$ (blue). Solid lines represent intermediate color varieties observed by the authors, and broken lines represent possible intermediate samples which were not available for this investigation. Samples containing $\mathrm{Ni}^{3+}$ and $\mathrm{Ni}^{2+}$ are green to blue-green; $\mathrm{Cr}^{3+}$ with $\mathrm{Ni}^{3+}$ produces reddish orange to orange; and $\mathrm{Ni}^{2+}$ with $\mathrm{Cr}^{3+}$ causes blue-violet to violet. The yellow sample (1.09 ct) measures $7.1 \times 5.2 \mathrm{~mm}$, and the blue sample $(2.70 \mathrm{ct})$ measures $9.5 \times 6.8 \mathrm{~mm}$. Photos by M. Glas.

all major commercial sources of natural ruby and sapphire. There are two basic types of natural yellow sapphire, which are caused predominantly by color centers or by $\mathrm{Fe}^{3+}$. Intermediate between red and yellow are chromium-bearing "padparadscha" sapphires. Blue to blue-violet natural sapphires are colored predominantly by $\mathrm{Fe}^{2+} / \mathrm{Ti}^{4+}$ ion pairs (metamorphic type) or by $\mathrm{Fe}^{2+} / \mathrm{Ti}^{4+}$ and $\mathrm{Fe}^{2+} / \mathrm{Fe}^{3+}$ ion pairs (basaltic type). Sapphires with intermediate colors exist in the blue-to-yellow $\left(\mathrm{Fe}^{3+}\right)$ and blue-to-red $\left(\mathrm{Cr}^{3+}\right)$ series (again, see figure 5).

Figure 5. This triangular diagram shows the colors of natural ruby and sapphires that are equivalent to the synthetic samples illustrated in figure 4. The three principal causes of color in natural corundum are $\mathrm{Cr}^{3+}$ (red to pink), color centers or $\mathrm{Fe}^{3+}$ (yellow), and $\mathrm{Fe}^{2+} / \mathrm{Ti}^{4+}$ ion pairs with or without additional $\mathrm{Fe}^{2+} / \mathrm{Fe}^{3+}$ pairs (blue to blueviolet). All intermediate colors are seen in natural corundum. Adapted from Schmetzer and Bank (1981).
Pleochroism. The pleochroism of both natural and synthetic corundum is identical for samples in the yellow-orange-red color range, including "padparad-

\section{Coloration of Natural Gem Corundum}

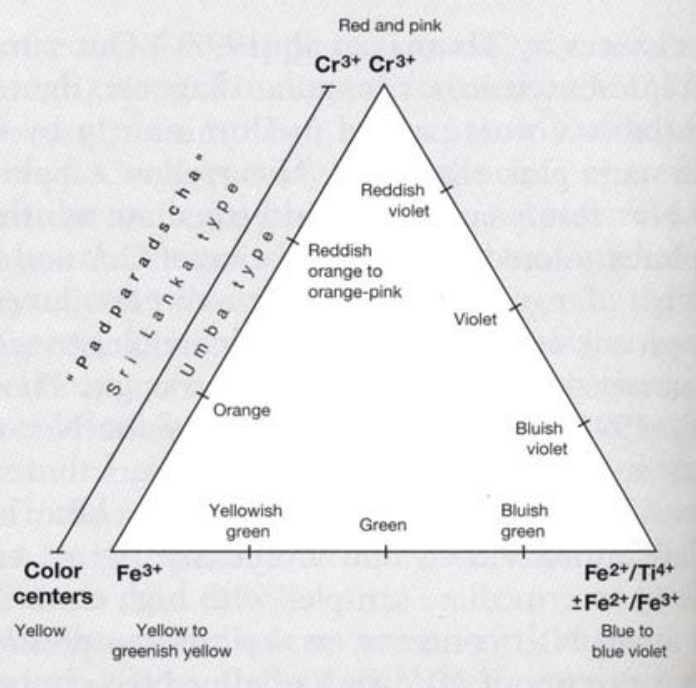


Figure 6. The blue synthetic sapphires showed diagnostic pleochroism that is the opposite of that seen in natural blue sapphire. In the

Russian hydrothermal synthetics, we saw reddish violet parallel to the $c$-axis and blue-green perpendicular

to it. Immersion, polarized light, magnified $40 \times$.
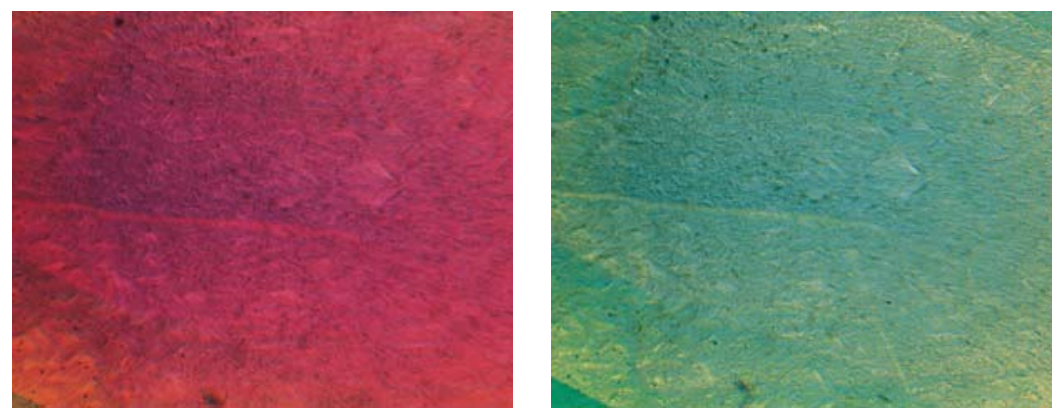

scha." Likewise, natural and synthetic reddish violet to bluish violet sapphires cannot be separated routinely by their pleochroism. However, pleochroism is a diagnostic feature of blue-to-green natural and synthetic sapphires.

Natural blue sapphire is predominantly colored by ion pairs of $\mathrm{Fe}^{2+}$ and $\mathrm{Ti}^{4+}$, with additional influence from $\mathrm{Fe}^{3+}$ or $\mathrm{Fe}^{2+} / \mathrm{Fe}^{3+}$ (or both) absorptions. All natural blue to blue-violet sapphires colored by the $\mathrm{Fe}^{2+} / \mathrm{Ti}^{4+}$ ion pair reveal distinct pleochroism: light blue or greenish blue, green, and yellowish green parallel to the c-axis, and intense blue, bluish violet, or violet perpendicular to the c-axis (Schmetzer and Bank, 1980, 1981; Schmetzer, 1987; Kiefert and Schmetzer, 1987).

The blue hydrothermal synthetic sapphires in the chromium-nickel series are colored predominantly by $\mathrm{Ni}^{2+}$. These sapphires revealed a distinct pleochroism of reddish violet parallel to the c-axis and blue-green perpendicular to the c-axis (figure 6) - the opposite of that seen in natural blue sapphire. Consequently, this difference in pleochroism is useful to separate natural and synthetic blue sapphire.

The pleochroism of the $\mathrm{Ni}^{2+}$ - and $\mathrm{Ni}^{3+}$-bearing blue-green to green synthetic sapphires (table 1) also differs from that of natural blue-green, bluish green, or green sapphires. Natural samples of this series contain relatively high amounts of $\mathrm{Fe}^{3+}$ (again, see figure 5); their pleochroism is yellowish green, green, or bluish green parallel to the c-axis and bluish green to blue perpendicular to the c-axis (Schmetzer and Bank, 1980, 1981; Schmetzer, 1987; Kiefert and Schmetzer, 1987). Using the techniques described above, we observed in their hydrothermal synthetic counterparts reddish orange to yellowish orange parallel to the c-axis and bluish green to yellowish green perpendicular to the c-axis (figure 7). * Consequently, pleochroism is also useful to distinguish hydrothermal synthetic sapphires in the blue-green to green series from their natural counterparts.
Orientation of Seeds and Morphology of the Rough. The morphology of the two rubies that were grown on spherical seeds is consistent with the description in Thomas et al. (1997).

As reported by Thomas et al. (1997) for the Tairus hydrothermal synthetic sapphires, the seed plates in the samples we examined were cut from Czochralski-grown colorless synthetic sapphire. In the complete crystals, the seed plates measured $30-40 \mathrm{~mm}$ in their longest dimension. Examination of these complete crystals, as well as of the sawn pieces, polished plates, and faceted stones that contained residual parts of the seed, revealed that the seed plates were cut in two different standard orientations: (1) parallel to the c-axis, that is, parallel to a first-order hexagonal prism $b\{10 \overline{1} 0\}$ (figure 8); and (2) at an inclination of about $32^{\circ}$ to the c-axis, that is, parallel to a negative rhombohedron $-r\{01 \overline{1} 1\}$ (figure 9). Seed plates cut in the latter orientation were not mentioned by Thomas et al. (1997), but they were seen in about half the samples we examined.

The crystals grown with seeds cut parallel to the prism $b$ revealed two large rough, uneven faces (see, e.g., figure 10) parallel to the seed, and two elongated faces each of the following forms: basal pinacoid $c\{0001\}$, positive rhombohedron $r\{10 \overline{1} 1\}$, and positive rhombohedron $\phi\{10 \overline{1} 4\}$ (figure 11A). In addition, these samples showed six smaller second-order hexagonal prism faces $a\{11 \overline{2} 0\}$. Occasionally, smaller $r$ faces and hexagonal dipyramids $n\{22 \overline{4} 3\}$ were also observed (figure 11B).

\footnotetext{
**Note that Thomas et al. (1997, p. 196) reported a strong violetish blue to blue-green pleochroism in the $\mathrm{Ni}^{2+} / \mathrm{Ni}^{3+}$-doped samples that they describe as blue-green. According to $S$. Z. Smirnov (pers. comm., 1999), the dichroism given in the Thomas et al. (1997) article represents colors seen in daylight in samples that were not crystallographically oriented. These colors are not identical to those determined parallel and perpendicular to the c-axis for oriented samples (see also table 1 of the present article). Note also that a small color shift is always observed between daylight and incandescent light with the immersion microscope (see the Materials and Methods section).
} 

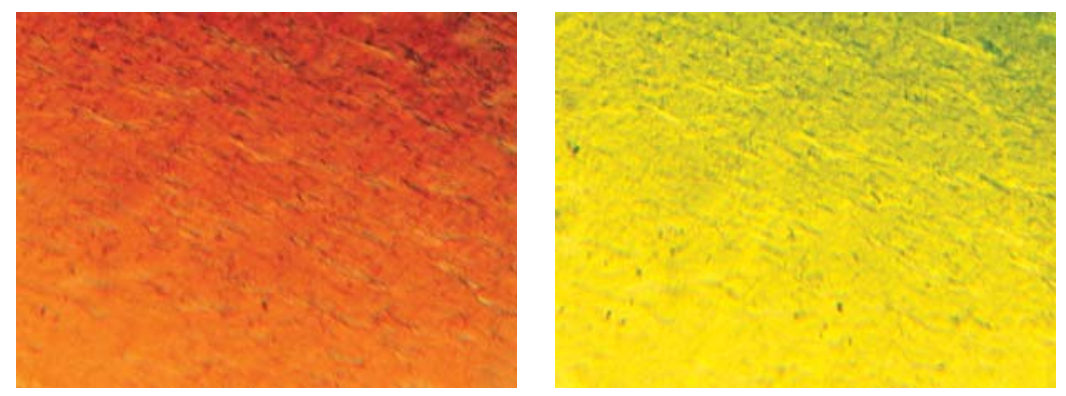

Figure 7. The pleochroism observed in the $\mathrm{Ni}^{2+}$ - and $\mathrm{Ni}^{3+}$ bearing blue-green to green synthetic sapphires also appears to be distinctive: reddish orange parallel to the c-axis, and yellowish green perpendicular to it. Immersion, polarized light, magnified $50 \times$.

Most of the crystals grown with $30-40 \mathrm{~mm}$ seeds cut parallel to the negative rhombohedron $-r$ $\{01 \overline{1} 1\}$ showed two large uneven faces parallel to $-r$, two relatively large, elongated faces parallel to a positive rhombohedron $r$, and striated, somewhat curved faces parallel to the basal pinacoid $c$ (figure 11C). In some samples, another elongated positive rhombohedron $\phi$ was also present (figures 11C and D). Adjacent to the uneven $-r$ faces were two large hexagonal dipyramids $n$; two smaller $n$ faces were developed adjacent to the positive rhombohedron $r$. In most cases, two smaller faces of the prism $a$ were observed perpendicular to the seed plane (figure 11D). Occasionally, smaller $r, \phi$, and $n$ faces also were present (figure 11C).

We do not know of any natural ruby or sapphire crystals with this morphology, especially with dominant $b$ or $-r$ faces. Consequently, crystals with this

Figure 8. This thin plate (approximately $1.2 \mathrm{~mm}$ thick) of a hydrothermal synthetic ruby crystal has been cut perpendicular to the colorless seed (visible at the bottom of the photo) to show characteristic growth zoning. The seed is oriented parallel to the c-axis. Three generations of synthetic ruby are revealed by the irregular boundaries that parallel the surface of the seed, which is oriented parallel to a hexagonal prism b $\{10 \overline{1} 0\}$. Numerous subindividuals-long, thin microcrystals—are also visible; color zoning is seen between different growth sectors of adjacent subindividuals.

Immersion, magnified $30 \times$.

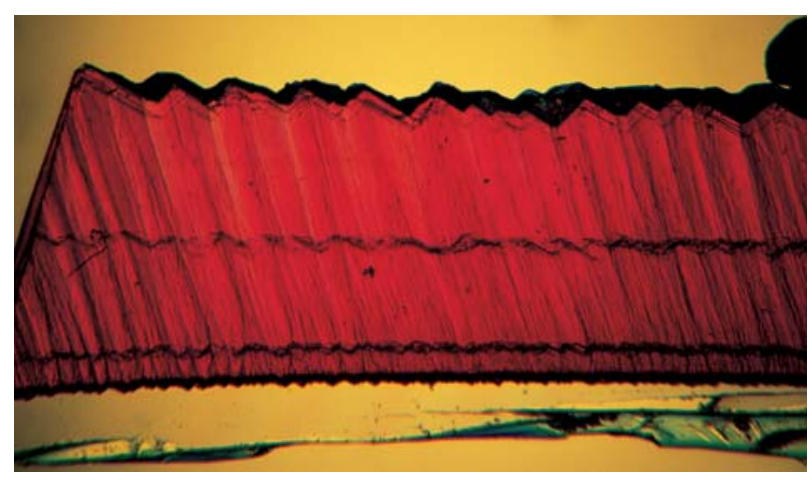

morphology can be easily recognized as synthetic.

In those samples grown with seed plates $30-40$ $\mathrm{mm}$ long, the two large uneven faces parallel to the seed dominated the morphology of the crystals (see, e.g., figures 3 and 11). In one relatively thick crystal, instead of an uneven face parallel to $-r$, alternating $n$ faces were seen (see figure 3 , inset). Where smaller seeds (i.e., 10-15 mm long) were used for the crystal growth, no external faces parallel to the seed were observed (figure 9). Therefore, crystals grown on smaller seed plates may not have either $b$ or $-r$ faces; synthetic crystals with such a morphology could be confused with natural ruby or sapphire.

Internal Growth Structures. Color Zoning. A difference in color from one growth sector to another, or in subsequent growth regions, was observed in some of the polished plates (see, e.g., figure 9). A

Figure 9. This $11.5 \times 6.5 \mathrm{~mm}$ plate $(0.8 \mathrm{~mm}$ thick) of a hydrothermal synthetic ruby, cut at an inclination of $30^{\circ}$ to the optic axis, shows the relationship of the crystal faces to the seed. The colorless seed is oriented parallel to a negative rhombohedron $-\mathrm{r}\{01 \overline{1} 1\}$. The synthetic ruby shows three hexagonal dipyramids $\mathrm{n}\{22 \overline{4} 3\}$ and one face of the positive rhombohedron $\mathrm{r}\{10 \overline{1} 1\}$. A color zoning is also seen between subsequent growth regions.

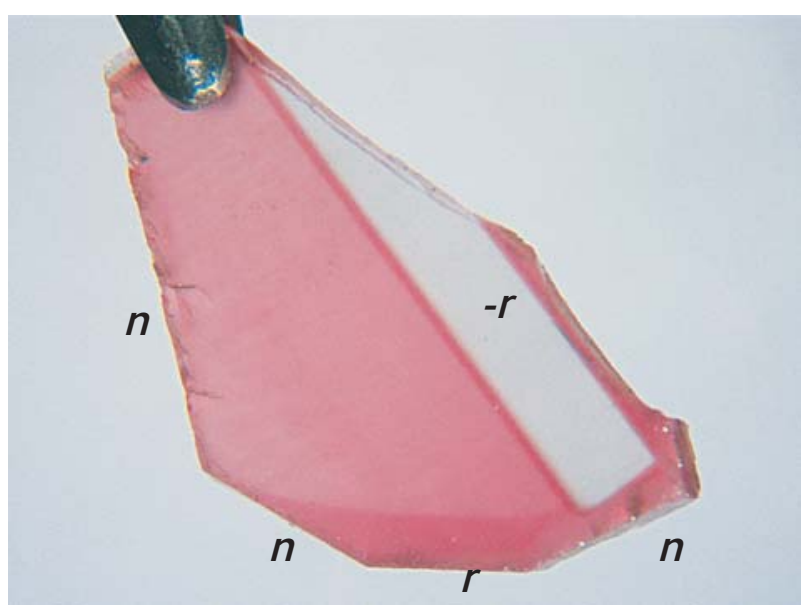


similar color distribution is frequently seen on a macroscopic scale in natural as well as flux-grown synthetic ruby and sapphire crystals. In the rough and faceted Russian hydrothermal synthetic rubies and sapphires, we did not observe any macroscopic color distribution in different growth sectors or regions that could be useful to distinguish these samples.

Growth Boundaries. Tairus hydrothermal synthetic corundum is routinely grown in a single autoclave run, rather than in several successive runs (S. Z. Smirnov, pers. comm., 1998). However, some of our samples revealed one or more distinct growth planes parallel to the seed (again, see figure 8). These planes represent boundaries between layers of synthetic corundum and indicate that these specimens grew in several intervals. They suggest that there were "interruptions" during the formation of these particular crystals, probably due to unintentional brief fluctuations in the power supply of the growth facility.

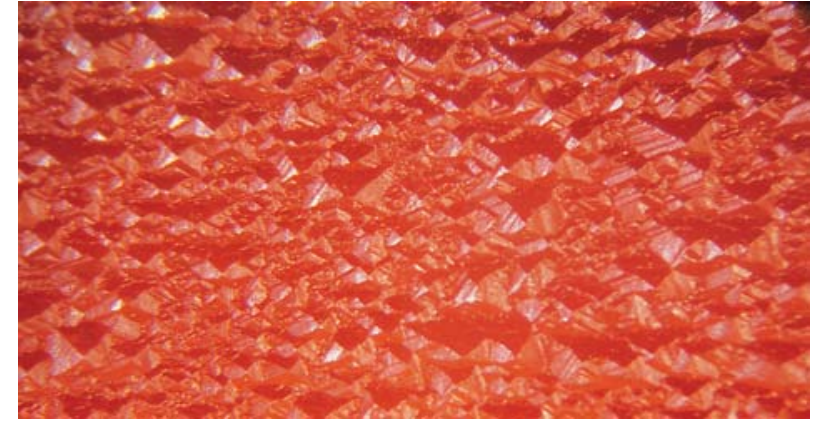

Figure 10. The rough surface texture of this orange hydrothermal synthetic sapphire crystal is formed by a distinct microstructure consisting of numerous long, thin microcrystals, as illustrated in figure 8. Magnified 20x.

Specific boundaries were also noted in all eight faceted samples (two synthetic rubies and six variously colored synthetic sapphires) that contained parts of the seed (see, e.g., figure 12). In general, these boundaries were associated with tiny copperbearing particles, as previously described by Peretti and Smith (1993) and Peretti et al. (1997). The cop-

Figure 11. The morphology of the synthetic ruby and sapphire crystals is controlled by the orientation of their seed plates. Crystals $A$ and $B$ were grown with tabular seeds cut parallel to a prism $\mathrm{b}\{10 \overline{1} 0\}$. On these crystals, uneven faces are developed parallel to $\mathrm{b}$; also present are the basal pinacoid $\mathrm{c}\{0001\}$, the prism a $\{1 \overline{1} \overline{0} 0\}$, positive rhombohedra $\mathrm{r}\{10 \overline{1} 1\}$ and $\phi\{10 \overline{1} 4\}$, and (in some cases) the hexagonal dipyramid $\mathrm{n}\{22 \overline{4} 3\}$. Crystals $C$ and $D$ were grown with tabular seeds cut parallel to a negative rhombohedron $-\mathrm{r}$ $\{0111\}$. Uneven faces are developed parallel to $-\mathrm{r}$; also shown are the basal pinacoid c $\{0001\}$, the prism a $\{11 \overline{2} 0\}$ (in D), positive rhombohedra $\mathrm{r}\{10 \overline{1} 1\}$ and $\phi\{10 \overline{1} 4\}$, and the hexagonal dipyramid $\mathrm{n}\{22 \overline{4} 3\}$.
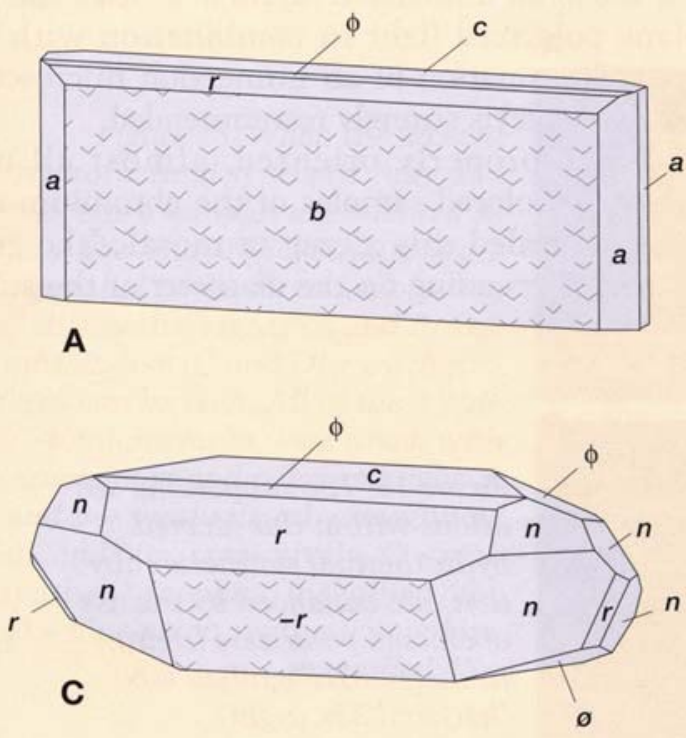
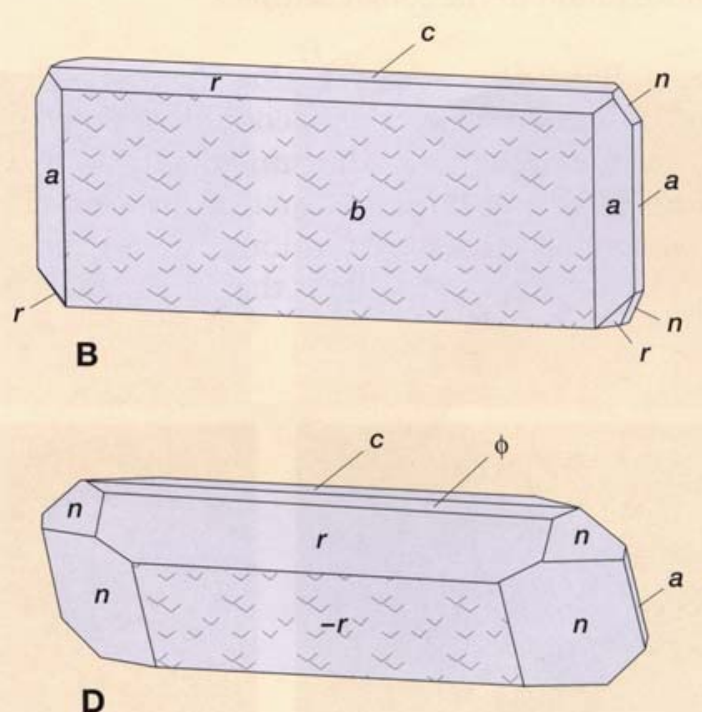


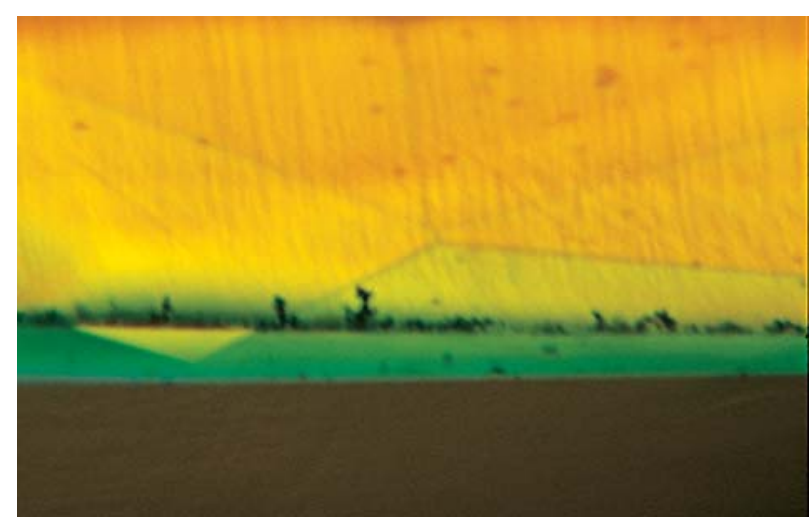

Figure 12. A portion of the seed is present along the table facet (flat lower surface) of this yellow hydrothermal synthetic sapphire. Adjacent to the seed are tiny copper-bearing particles. The faint striations oriented nearly perpendicular to the seed represent subgrain boundaries between long, thin microcrystals within the larger crystal. (The area around the table facet appears green because of dispersion.) Immersion, magnified 50x.

per in these inclusions originates from the wires used to mount the seed plates, from the seals of the autoclave, and/or from the buffers used during crystal growth (see also Thomas et al., 1997). In some of these faceted samples, the boundaries between seed and overgrowth were oriented parallel to a prism face; in the others, they were parallel to a rhombohedral face. Consequently, the two types of seed orientation in these faceted samples were consistent with those found in the rough samples.

Subgrain Boundaries and Color Zoning. The Russian hydrothermal synthetic corundum crystals consist of numerous long, thin microcrystals that are observed at a specific inclination to the seed plate, depending on its orientation. The terminations of these microcrystals form the rough, uneven surfaces that are parallel to the seed plate on the crystals (again, see figures 8 and 10). This growth pattern has been described by Voitsekhovskii et al. (1970) for hydrothermally grown synthetic corundum as a "microblock" structure that consists of an assemblage of fine (0.05 to $0.5 \mathrm{~mm}$ in diameter) elongated crystals that are disoriented relative to one another by not more than 1-3 minutes of arc.

These long, thin microcrystals form a diagnostic growth pattern that is associated with a distinct type of fine-scale color zoning observable in immersion. In thin $(1-2 \mathrm{~mm})$ plates cut perpendicular to the seed, the variable intensity in color between growth sectors of adjacent subindividuals is clearly visible (figure 8). In thicker plates, or in faceted samples, in the same orientation, only the boundaries between the differently colored growth sectors can be seen, in the form of subparallel (i.e., not perfectly parallel) striations (figure 13). The use of crossed polarizers often can enhance the contrast between growth sectors (figures 13 and 14).

An even more characteristic internal growth pattern is seen in a view parallel to these striations. To find the best - that is, most diagnostic - direction of view in faceted samples, search first for the presence of the subparallel striations, then turn the faceted stone to a direction in which the striations are parallel to the direction of view. Only in this orientation is it possible to see the zigzag or mosaic-like growth pattern that is most distinctive of this material (figure 15). Although this growth pattern sometimes may be seen without immersion (see Sechos, 1997), the use of an immersion liquid or at least the use of plane polarized light in combination with fiberoptic illumination (if an immersion microscope is not available) is strongly recommended.

When properly oriented, almost all of the intensely colored samples of the chromium-nickel series revealed this zigzag or mosaic-like growth pattern. Depending on the diameter of the subindi-
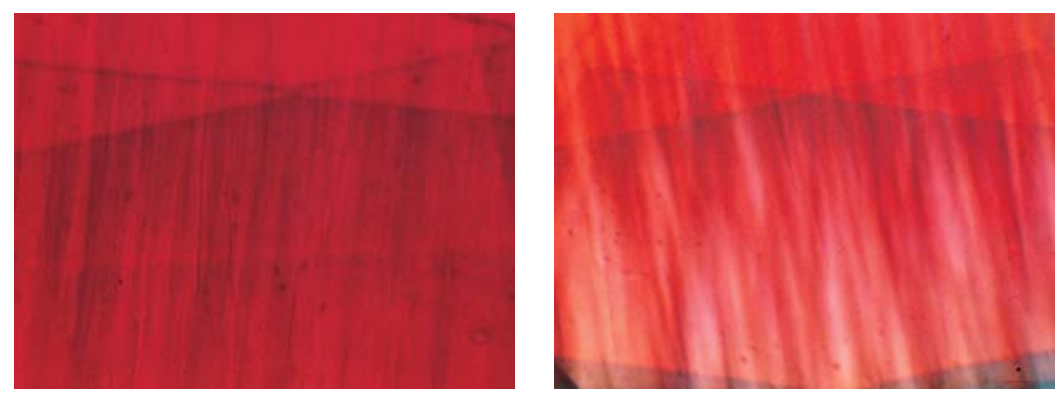

Figure 13. The subparallel striations within this faceted hydrothermal synthetic ruby (left) are enhanced by the use of crossed polarizers (right). Immersion; magnified 40x (left) and $35 \times($ right). 
viduals that form the synthetic corundum crystal, the color zoning may vary from fine to coarse in texture. With training, however, the gemologist can recognize the striations and zigzag or mosaic-like patterns in synthetic rubies and sapphires that have sufficient color saturation, with the exception of yellow synthetic sapphires colored by $\mathrm{Ni}^{3+}$ alone. In only one of the four yellow samples with no evidence of $\mathrm{Cr}^{3+}$ in the absorption spectrum did we observe extremely weak striations (figure 12). In addition, no diagnostic growth pattern was found in two light blue, almost colorless, samples in which $\mathrm{Ni}^{2+}$ was the predominant cause of color as proved by absorption spectroscopy and EDXRF analysis.

Although growth patterns associated with color zoning are also observed frequently in natural rubies and sapphires (figure 16), these patterns are very different from those seen in the synthetic samples. In general, natural rubies and sapphires are not composed of numerous long, thin microcrystals with slightly different orientations. Thus, growth patterns in natural samples are mainly caused by color zoning due to growth fluctuations within a single crystal. The mosaic-like pattern in hydrothermal synthetic rubies and sapphires is strongly diagnostic, and no chemical or spectroscopic examination is necessary when it is present. However, UV-Vis or infrared spectroscopy in combination with trace-element analysis may be necessary to identify the yellow synthetic sapphires, as well as extremely pale samples of other hues.

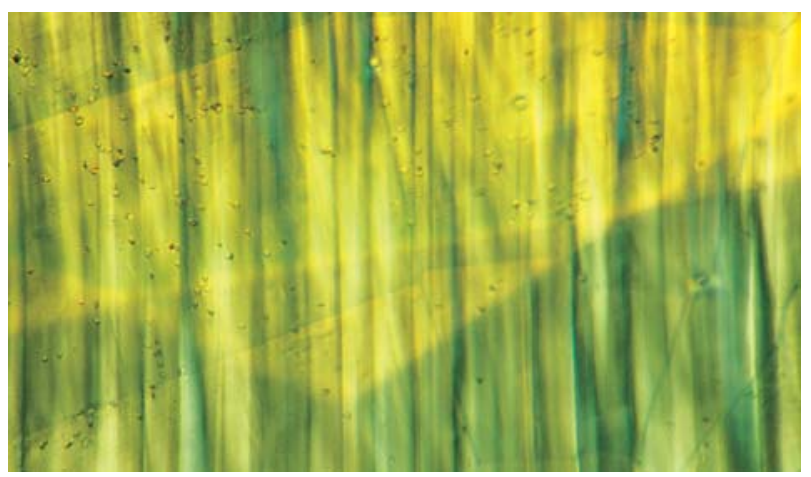

Figure 14. In this faceted blue-green synthetic sapphire, as in the synthetic ruby in figure 13, one can see striations representing oriented subgrain boundaries between the long, thin microcrystals. Immersion, crossed polarizers, magnified $70 x$.

\section{CONCLUSION}

The hydrothermally grown nickel- and/or chromium-doped Russian synthetic rubies and sapphires examined revealed an external morphology and internal growth features that reflect their formation conditions. The identification of characteristic growth patterns is a relatively straightforward method to distinguish most of these synthetics from their natural counterparts. A horizontal microscope with immersion or a standard gemological microscope with fiber-optic illumination in combination with polarizing filters is all that is needed to carry out this investigation.
A

Figure 15. When the faceted hydrothermal synthetic ruby and sapphire samples are oriented so that the subparallel striations are parallel to the direction of view, distinctive zigzag ( $A$ and $B$ ) and mosaic-like (C and D) growth patterns can be seen. All of these pho-

tomicrographs were taken with immersion and polarized light. A and $B=$ synthetic ruby, magnified $50 \times$ and $60 \times$, respectively; $C=$ pink synthetic sapphire, magnified $40 x$; $D=$ blue-green synthetic sapphire, magnified 45x.

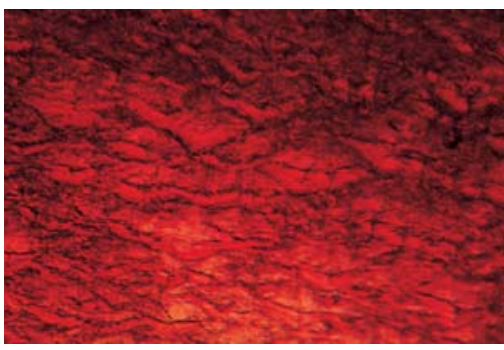

C

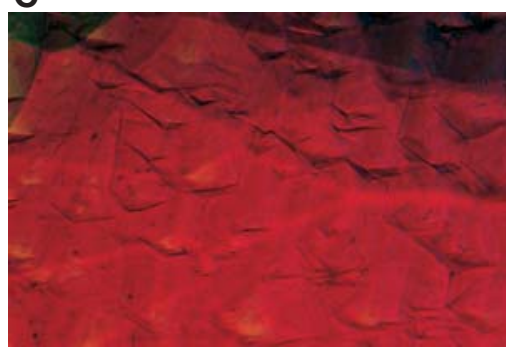

B

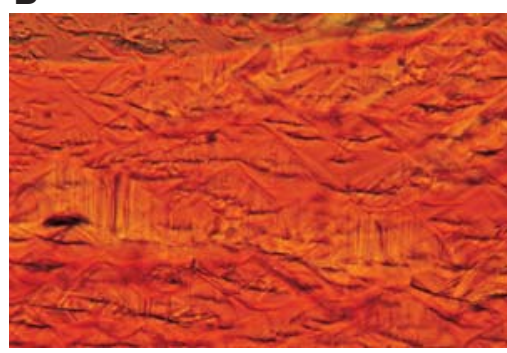

D

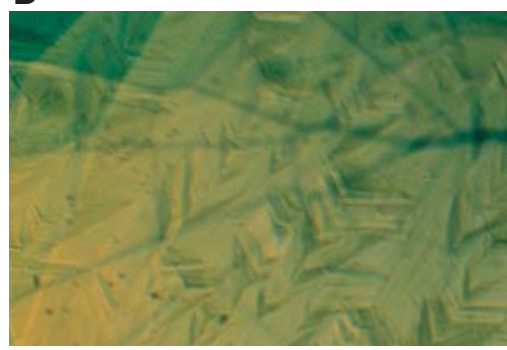




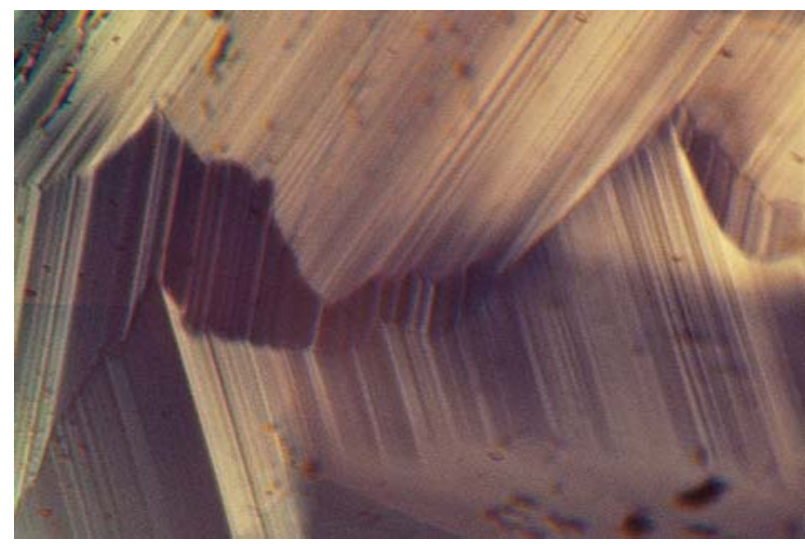

Figure 16. Growth patterns are frequently seen in natural rubies and sapphires, as in this blue sapphire from Andranondambo, Madagascar. This pattern is not related to microstructures consisting of subindividuals that reveal color zoning between various growth sectors. In this case, the pattern consists of growth planes parallel to one $\mathrm{r}$ and two $\mathrm{n}$ faces. Adjacent growth sectors show changes in size and color intensity. Immersion, magnified $50 \times$.
The characteristic internal features of these hydrothermal synthetic rubies and sapphires are: (1) subparallel striations; and (2) a distinct zigzag or mosaic-like growth structure, associated with color zoning between different growth sectors of adjacent subindividuals. The latter can be seen only when the sample is viewed in a direction parallel to the striations. Only the yellow hydrothermal synthetic sapphires and extremely light blue samples did not show any of these diagnostic internal growth characteristics. In the absence of other distinctive inclusions, such corundums will require additional testing by spectroscopic or analytical techniques such as UV-visible absorption spectroscopy or EDXRF.

Pleochroism is also useful to identify some hydrothermal synthetic sapphires, particularly to distinguish chromium-free samples of the blue-togreen series from their natural counterparts. To perform this test, the orientation of the optic axis in a faceted sample must first be determined.

\section{REFERENCES}

Hänni H.A. (1983) Weitere Untersuchungen an einigen farbwechselnden Edelsteinen. Zeitschrift der Deutschen Gemmologischen Gesellschaft, Vol. 32, No. 2/3, pp. 99-106.

Keller P.C., Koivula J.I., Jara G. (1985) Sapphire from the Mercaderes-Río Maya area, Cauca, Colombia. Gems ↔) Gemology, Vol. 21, No. 1, pp. 20-25.

Kiefert L., Schmetzer K. (1987) Blue and yellow sapphire from Kaduna Province, Nigeria. Journal of Gemmology, Vol. 20, No. $7 / 8$, pp. 427-442.

Kiefert L., Schmetzer K. (1991) The microscopic determination of structural properties for the characterization of optical uniaxial natural and synthetic gemstones, part 1: General considerations and description of the methods. Journal of Gemmology, Vol. 22, No. 6, pp. 344-354.

Peretti A., Mullis J., Mouawad F., Guggenheim R. (1997) Inclusions in synthetic rubies and synthetic sapphires produced by hydrothermal methods (TAIRUS, Novosibirsk, Russia). Journal of Gemmology, Vol. 25, No. 8, pp. 540-561.

Peretti A., Smith C.P. (1993) A new type of synthetic ruby on the market: Offered as hydrothermal rubies from Novosibirsk. Australian Gemmologist, Vol. 18, No. 5, pp. 149-157.

Peretti A., Smith C.P. (1994) Letter to the Editor. Journal of Gemmology, Vol. 24, No. 1, pp. 61-63.

Schmetzer K. (1986) An improved sample holder and its use in the distinction of natural and synthetic ruby as well as natu$\mathrm{ral}$ and synthetic amethyst. Journal of Gemmology, Vol. 20, No. 1, pp. 20-33.

Schmetzer K. (1987) Zur Deutung der Farbursache blauer
Saphire-eine Diskussion. Neues Jahrbuch für Mineralogie Monatshefte, Vol. 1987, No. 8, pp. 337-343.

Schmetzer K. (1988) Characterization of Russian hydrothermallygrown synthetic emeralds. Journal of Gemmology, Vol. 21, No. 3, pp. 145-164.

Schmetzer K., Bank H. (1980) Explanations of the absorption spectra of natural and synthetic Fe- and Ti-containing corundums. Neues Jahrbuch für Mineralogie Abhandlungen, Vol. 139 , No. 2, pp. 216-225.

Schmetzer K., Bank H. (1981) The colour of natural corundum. Neues Jahrbuch für Mineralogie Monatshefte, Vol. 1981, No. 2, pp. 59-68.

Schmetzer K., Bank H., Gübelin E. (1980) The alexandrite effect in minerals: Chrysoberyl, garnet, corundum, fluorite. Neues Jahrbuch für Mineralogie Abhandlungen, Vol. 138, No. 2, pp. $147-164$.

Sechos B. (1997) Identifying characteristics of hydrothermal synthetics. Australian Gemmologist, Vol. 19, No. 9, pp. 383-388.

Smith C.P. (1996) Introduction to analyzing internal growth structures: Identification of the negative $d$ plane in natural ruby. Gems e) Gemology, Vol. 32, No. 3, pp. 170-184.

Thomas V.G., Mashkovtsev R.I., Smirnov S.Z., Maltsev V.S. (1997) Tairus hydrothermal synthetic sapphires doped with nickel and chromium. Gems «) Gemology, Vol. 33, No. 3, pp. $188-202$.

Voitsekhovskii V.N., Nikitichev P.I., Smirnova Z.F., Furmakova L.N. (1970) The microblock structure of hydrothermal crystals of corundum. Soviet Physics-Crystallography, Vol. 14, No. 5, pp. 733-735. 